\title{
ADAPTAÇÃO DE UM INQUÉRITO ALIMENTAR A SER UTILIZADO EM UM ESTUDO LONGITUDINAL A PARTIR DO CONTEXTO SOCIOCULTURAL DE UMA POPULAÇÃO DE COLONIZAÇÃO ALEMÃ
}

\author{
ADAPTATION OF A DIETARY SURVEY FOR USE IN A LONGITUDINAL STUDY FROM THE \\ SOCIOCULTURAL CONTEXT OF A POPULATION OF GERMAN COLONIZATION
}

\author{
Ana Carolina Da Rosaa, Bruna Schmitz ${ }^{\text {b }}$, Graciella Chiarellic, João Luiz Gurgel \\ Calvet da Silveira ${ }^{d}$, Maria Urania Alves ${ }^{e}$, Luciane Coutinho de Azevedo Campanella ${ }^{f}$ \\ aanazimba@gmail.com, bbru_schmitz92@hotmail.com, cgraci_chiarelli@yahoo.com.br, \\ dgurgeljl@gmail.com, ealvesmariaurania@gmail.com, flu.cda@hotmail.com \\ Universidade Regional de Blumenau - Blumenau (SC), Brasil
}

Data de recebimento do artigo: 25/01/2016 Data de aceite do artigo: 16/08/2016

\section{RESUMO}

Introduçáo. Os instrumentos de avaliação de hábitos alimentares precisam ser validados considerando as especificidades dos costumes de consumo dos grupos populacionais, sempre culturalmente determinados. Objetivo. Apresentar uma metodologia para adaptaçáo de um instrumento de avaliaçáo do padráo de ingestão alimentar - o questionário de frequência alimentar (QFA) - para população do município de Pomerode, SC. Metodologia. Abordagem qualitativa, utilizando grupos focais como técnica. A partir da exploração, codificação e análise do material coletado nos grupos focais, foram realizadas 21 inclusôes e 17 exclusôes de alimentos do QFA de partida, na ordem de 33,33\% de alteraçốes. Consideraçóes. A utilizaçáo dos grupos focais demonstrou ser uma técnica apropriada para a adaptação do questionário de frequência alimentar, resultando em inclusóes e exclusóes de alimentos identificados pelos próprios participantes no seu contexto sociocultural, qualificando etapa prévia para validação e reprodutibilidade, para que a partir de seus resultados sejam obtidas informaçôes dietéticas corretas e úteis para posteriores inferências.

Palavras-chave: Ingestão alimentar; epidemiologia nutricional; questionários; características culturais.

\section{ABSTRACT}

Introduction. The assessment tools in dietary habits need to be validated considering the specificities of the culturally determined eating habits of the population groups. Objective. To present a methodology to adapt an instrument for assessing the pattern of food intake - the food frequency questionnaire (FFQ) for population of the municipality of Pomerode, SC, Brazil. Methodology. A qualitative approach using focus groups as a technique. From the exploration, coding and data analysis of the material collected, 21 foods were added and 17 were excluded from the starting FFQ, resulting in $33.33 \%$ of changes. Considerations. The use of focus groups proved to be an appropriate technique for the adaptation of the food frequency questionnaire, resulting in food inclusions and exclusions identified by the participants themselves in their sociocultural context, qualifying the preceding step for validation and reproducibility, so that from their results, correct and useful dietary information for subsequent inferences can be obtained.

Keywords: Food intake; nutritional epidemiology; questionnaires; cultural characteristics. 


\section{Introdução}

Os estudos de coorte, também chamados de seguimento ou de follow-up, são os únicos capazes de abordar hipóteses etiológicas produzindo medidas de incidência e, consequentemente, medidas de risco ${ }^{1}$. O estudo de coorte Study of Health In Pomerania (SHIP), realizado na Alemanha, na região da Pomerânia, pela Universidade Greifswald, constitui um abrangente estudo sobre condições de saúde associadas a fatores de risco de natureza biopsicossocial ${ }^{2}$.

Com o objetivo de comparar os resultados entre populaçóes que apresentassem constituição genética semelhante, porém com fatores socioambientais e culturais bastante diversos, no Brasil, a Universidade Regional de Blumenau iniciou, em parceria com a Universidade de Greifswald, o multicêntrico Estudo das Condiçôes de Vida e Saúde da População de Pomerode/SC (SHIP Brasil), no município de Pomerode/SC, região que apresenta o maior número de descendentes de imigrantes da Pomerânia no mundo, reunindo as condiçóes ideais para este estudo.

Dentre os fatores determinantes da saúde da populaçáo estudada se destacam aqueles referentes ao padrão de consumo alimentar. $\mathrm{O}$ questionário de frequência alimentar (QFA) é considerado um método ideal para avaliar a ingestáo dietética e sua relação com doenças crônicas ${ }^{3,4}$; tem a capacidade de classificar os indivíduos segundo seus padrôes alimentares habituais, além de ser um instrumento de fácil aplicabilidade e baixo custo, o que viabiliza sua utilização em estudos epidemiológicos ${ }^{5,6}$.

Uma vez que o QFA é um instrumento culturalmente específico, pois considera que dentro do mesmo grupo populacional há diferentes grupos demográficos e subgrupos com peculiaridades culturais diferentes, é importante escolher cuidadosamente o método de referência adequado para cada estudo ${ }^{7}$.

Há diferentes pesquisas que envolvem o desenvolvimento e a validaçáo de novos QFAs, no entanto, destaca-se a ausência de instrumentos validados e reprodutíveis que possibilitem a medição, com confiança e precisão, de grupos populacionais a partir dos seus hábitos alimentares específicos e culturalmente determinados, como é o caso dos moradores de Pomerode, SC. Essa situação ainda se constitui como uma das maiores dificuldades ao se estudar a relação dieta/doença ${ }^{8,9}$.

A partir do problema apresentado, considerando que todo método de avaliaçáo de ingestáo alimentar estruturado possui limitaçóes, sendo fundamental adaptar o instrumento de forma mais adequada para cada situação $^{10}$, o objetivo deste trabalho é apresentar uma metodologia de adaptaçáo de um instrumento de avaliaçáo da QFA para ser utilizado no estudo de coorte SHIP Brasil.

\section{Metodologia}

Adotou-se, neste trabalho, como metodologia uma abordagem exploratória qualitativa. A fim de proceder a uma análise crítico-interpretativa sobre os hábitos alimentares da populaçáo residente na regiáo de Pomerode, SC, foram coletados dados a partir de discussóes focadas em tópicos específicos e diretivos, utilizando como técnica grupos focais

Em conversa preliminar com a Secretaria de Saúde de Pomerode, foram elencadas para realizaçáo dos grupos focais três Unidades de Saúde Básica (USB) que abrangeriam o maior número de pessoas da área rural, típica e urbana. Enfermeiros e agentes de saúde dessas unidades foram os responsáveis por convidar as pessoas da sua área de abrangência para o encontro. $\mathrm{O}$ quarto grupo focal foi realizado no Parque Municipal de Eventos (período noturno) com os voluntários que trabalhavam e não poderiam comparecer durante o dia na UBS.

Participaram dos grupos focais moradores locais que não eram familiares entre em si e nem pertenciam ao mesmo círculo de amizade. Os participantes foram selecionados por faixas etárias, correspondentes às mesmas dos entrevistados no estudo SHIP da Alemanha, e distribuídos em três grupos focais: GF1 (com idade de 20 a 39 anos), GF2 (de 40 a 59 anos) e GF3 (de 60 a 80 anos); o quarto grupo focal (GF4) foi realizado com um grupo de especialistas em alimentação e nutrição que reside e atua em instituições públicas ou privadas de Pomerode, SC.

Pomerode se localiza no Médio Vale do Rio ItajaíAçú, com cerca de 30 mil habitantes. A educação e economia são os atuais grandes destaques do município. A cidade é considerada um forte polo têxtil e metalomecânico, com a indústria representando $72 \%$ da ocupação de seus habitantes, enquanto $10 \%$ vivem da agricultura e os outros $18 \%$ se dividem em serviços e comércio ${ }^{11}$.

Cada grupo foi composto por 6 a 10 participantes, totalizando 37 pessoas entrevistadas, homens e mulheres, que realizavam a maioria das refeiçóes no domicílio. Conforme Iervolino e Pelicioni ${ }^{12}$, os grupos focais devem ser compostos por 6 a 10 pessoas, que não possuam nenhum grau de parentesco entre si. Os participantes assinaram um Termo de Consentimento Livre Esclarecido (TCLE) antes da realização da pesquisa.

A metodologia utilizada para a realização dos grupos focais foi a apresentação audiovisual na forma de slides para ilustração dos alimentos do QFA adotado no Estudo Longitudinal de Saúde do Adulto (ELSA Brasil $)^{10}$, servindo como instrumento base para a elaboração do QFA específico para a população em estudo. O QFA ELSA Brasil é composto por 114 alimentos, subdivididos em sete grupos alimentares de pães, cereais e tubérculos; frutas; verduras, legumes e leguminosas; ovos, carnes, leite e derivados; massas e outras preparaçōes; 
doces e bebidas, com uma opção para preenchimento de quantidade e nove opçóes de frequência de consumo.

A análise de dados ocorreu por meio da transcriçáo, na íntegra, dos áudios gravados nas reunióes, para posterior levantamento do consumo alimentar habitual dos moradores, para que o QFA de partida pudesse ser adaptado e, assim, um novo QFA fosse criado para sua utilização no SHIP Brasil.

Para análise dos dados qualitativos, recolhidos por meio das sessóes de grupo focal, as gravaçóes dos encontros foram transcritas em sua integralidade e posteriormente analisadas. Em um primeiro momento, foi realizada a leitura flutuante das transcriçóes de todos os encontros. Após essa leitura, iniciou-se a identificação dos diferentes alimentos apontados como comumente consumidos, pouco consumidos ou raramente consumidos na maioria dos grupos. Esses dados foram agrupados para posterior categorização e análise. Dessa forma, foi possível identificar quais alimentos constavam no questionário e eram pouco ou raramente consumidos, assinalando para sua exclusão do questionário. Da mesma forma, foi possível identificar quais alimentos apareciam como comumente consumidos e não constavam no questionário, indicando sua inclusão.

Este trabalho foi submetido à análise e aprovado pelo Comitê de Ética em Pesquisa em Humanos (CEPH) da Fundação Universidade Regional de Blumenau (FURB), sob o registro CAAE de no 25616514.4.0000.5370.

\section{Resultados e discussão}

Neste estudo, a escolha da utilização de grupos focais se deu em virtude da interação, da troca de experiência e do debate que ocorrem nesse método entre o pesquisador e os participantes ${ }^{12,13}$. Conforme recomendado por Iervolino e Pelicioni ${ }^{12}$, cada grupo focal deve ter um moderador, que cria um ambiente propício para que diferentes percepçôes e pontos de vista venham à tona, possibilitando aos participantes chegarem a um consenso (Tabelas 1 e 2).

Tabela 1: Alimentos excluídos, pouco ou raramente consumidos pela população pesquisada.

\begin{tabular}{ccc}
\hline & Alimentos excluídos & \\
\hline Angu & Cajá & Muçarela de búfala \\
\hline Cará & Almeirão & Queijo polengui \\
\hline Inhame & Quiabo & Caranguejo \\
\hline Banana da terra cozida & Pistache & Comida baiana (vatapá, caruru e moqueca de peixe) \\
\hline Caju & Cottage & Pão sírio \\
\hline Siri & Acarajé & \\
\hline
\end{tabular}

Fonte: Elaborado pelos autores.

Tabela 2: Alimentos incluídos, comumente consumidos pela população pesquisada.

\begin{tabular}{|c|c|c|}
\hline \multicolumn{3}{|c|}{ Alimentos incluídos } \\
\hline Pão frito na banha & Biscoito amanteigado & Queijo de colono \\
\hline Pão com sardinha e ovo & Maionese caseira & Kochkäse \\
\hline Apfelstrudel & Nêspera (ameixa do pé) & Bolinho de carne \\
\hline Orelha de gato & Leite de colono & Gordura de porco \\
\hline Recheio de pato ou marreco & Língua & Chopp \\
\hline Nhoque de batata doce & Cuca & Nata \\
\hline $\begin{array}{c}\text { Morcilha clara (Leberwurst) e escura } \\
\text { (Blutwurst) }\end{array}$ & Geleia de cabeça de porco (sülse) & Sopa de sangue de pato (Schwarzsauer) \\
\hline
\end{tabular}

Fonte: Elaborado pelos autores.

Os grupos focais nada mais são do que pessoas que dialogam entre si a respeito de um tema. Para esse fim, os integrantes recebem estímulos apropriados para que ocorra o debate. Esse tipo de grupo consiste na interação entre 
os participantes e o pesquisador, que tem como objetivo colher dados a partir de uma conversa focada. Assim, o grupo focal constitui-se em uma técnica de pesquisa qualitativa, se diferenciando de outras por possuir características próprias, principalmente a interação, que possibilita um aprofundamento do tema, potencializando a geração de dados. Além disso, permite compreender o tema abordado no contexto do dia a dia da população ${ }^{12,13}$.

Uma vez que o consumo habitual dos alimentos que compunham os grupos alimentares do QFA de partida representaram os principais eixos geradores do debate, os resultados encontrados nos grupos focais, frutos das discussões, serão apresentados conforme as subunidades adotadas, a fim de obedecer a uma linha lógica de apresentação das respostas, que serão transcritas em parte, de forma literal.

\section{Grupo dos pães, cereais e tubérculos}

A partir das falas dos depoentes, verificou-se que os alimentos habitualmente consumidos nesse grupo alimentar já faziam parte do QFA de partida. Foi relatado consumo rotineiro de arroz - principalmente o refinado -, batata e aipim, denominaçáo designada para mandioca. Destaca-se que a batata é um alimento típico em toda a cultura alimentar europeia, sendo muito utilizada na culinária alemá em diversos pratos ou acompanhando diferentes molhos ${ }^{14,15}$.

(GF4): "O pessoal de Pomerode consome muito aquele trio de, arroz, batata e aipim... bastante batatas... batata doce frita também”. (GF1 e GF3): "Em todo casamento tem aipim frito com bacon".

(GF2): "Na regiẫo o aipim é campeão... aipim frito, né, com sangue de pato... não há lugar em Pomerode que não tenha uma rocinha de aipim".

Entre os entrevistados que afirmaram hábito de consumo de cereais e tubérculos, foi observada também frequência elevada de ingestão de farinhas, especificamente de mandioca e milho, presentes no QFA - exceto cará, inhame e angu, que foram excluídos, conforme relatos a seguir:

(GF1): "Eu vejo o pessoal comprar muito o fubá... só o cará e o inhame que não...".

(GF4): "Farinha de milho é um alimento muito ingerido na localidade Texto Rega, Pomerode Fundos".

(GF3): "Aqui se consome farinha de milho e de mandioca. $O$ angu nâo... o inhame ninguém come...".

Nesse grupo alimentar também se ressaltou o consumo de produtos de panificação. Muitos alimentos que já faziam parte do QFA de partida, como o pão caseiro, de trigo e integral - exceto o páo sírio, que foi extraído do questionário inicial -, bolos e tortas.
(GF1): "Se consome aqui pão caseiro, pão francês... muito bolo seco também e nega maluca...".

(GF4): "Pão sírio, não! Bolo simples sim...".

(GF2): "Tem aquele pão amanhecido. É, tipo rabanada, frito na banha".

Percebeu-se nos relatos durante os grupos focais ênfase na ingestão de alimentos regionais, como parte do hábito alimentar local, com características de preparo inerentes àquela regiáo, tais como: páo frito na banha, apfelstrudel, torta alemá, cuca, sonho e orelha de gato, bem como a presença do hábito de realizar determinadas refeições ao longo do dia (no lanche da manhã), com alimentos típicos (pão frito com sardinha e ovo).

(GF3 e GF4): "O que é muito consumido aqui é o apfelstrudel, a torta alemã e a cuca... Em todas as festas, tem cuca e rocambole".

(GF4): "Muitas pessoas têm hábito de parar na padaria depois do trabalho, comprar uma cuca e levar para casa".

(GF4): "Em festas de casamento aqui, depois do jantar tem cuca ao invés de docinhos...".

(GF1): "Sonho é uma coisa que sai bem aqui... feito como as omas [vovós] faziam".

Além disso, algumas falas revelaram a inclusão nos costumes alimentares diários dos biscoitos amanteigados produzidos e comercializados entre os moradores de Pomerode, demonstrando forte influência no consumo alimentar dos indivíduos daquela região, conforme suas tradiçóes.

(GF4, GF1 e GF3): "Doce aqui é o biscoitinho amanteigado. Pode ser o de natal, com goiaba... Amanteigado é o top!".

Esses depoimentos nos levam ao entendimento de que os participantes possuem hábitos muito característicos: a alimentação dessa população de origem alemã em geral está concentrada em alimentos típicos, como massas, gorduras, açúcares e carne $e^{16}-$ aspecto preocupante, uma vez que seu consumo frequente é prejudicial à manutenção da boa saúde.

\section{Grupo de frutas e verduras, legumes e leguminosas}

Foi possível identificar a presença de todas as frutas do QFA inicial no hábito alimentar dos participantes dos grupos focais, além da ameixa do pé, incluída no questionário final. Percebeu-se também que, segundo os avaliados, a populaçáo possui o costume de utilizar as frutas de maneira particular. De acordo com Braun ${ }^{17}$ : geleias 
e doces para passar no páo ou para comer de sobremesa eram feitas com todas as frutas que havia no sítio.

(GF2): "As frutas todas elas aparecem lá em casa, são todas bem-vinda".

(GF1): "As frutas eles não consomem in natura, é muita calda”.

(GF4): "Abacate com açúcar e limão bastante”.

A produção de geleias e chucrute começou nos tempos de guerra, pois nesse modo de preparo o tempo de conservação dos produtos se tornava maior. Além da guerra, outro fator importante para essa prática é a grande quantidade de alimentos produzidos de acordo com a sazonalidade, sendo desperdiçados quando não preparados como geleias e chucrute ${ }^{14}$.

Nos grupos focais também foi referido elevado consumo de hortaliças e legumes, com destaque para o repolho, ingerido na forma in natura, como chucrute e também para recheios de pato e marreco. $\mathrm{O}$ único alimento excluído do QFA de partida foi o quiabo, citado como não presente no dia a dia dos entrevistados.

(GF1): "Esse repolho roxo é o que mais vai".

(GF4): "O campeão ali é o repolho".

(GF3): "Tem também a parte de rechear o repolho. É, com carne moída".

(GF1 e GF2): "O quiabo eu já vi, mais nunca preparei e nunca comi".

Vale ressaltar que na região analisada há grande presença de área rural, além da maior parte da população morar em casas, com áreas livres para plantio doméstico, aspecto que favorece a ingestão de frutas, legumes e hortaliças, em decorrência da redução do seu custo final.

Conforme Nascimento e colaboradores ${ }^{18}$, o quintal nas residências é uma das variáveis do ambiente que exerce influência sobre o estado nutricional da população, porque existe uma correlação positiva entre os produtos dos quintais e a frequência de seu consumo pelas famílias.

Ademais, o clima subtropical, típico dessa região, determina o consumo sazonal de diversas espécies, de acordo com a época para crescimento e maturação durante as diferentes estações. A sazonalidade - alteração em determinadas épocas do ano - é de suma importância no momento da comercializaçáa e do consumo de frutas e hortaliças ${ }^{19}$.

\section{Grupo de ovos, carnes, leites e derivados}

Dentre os grupos alimentares do QFA inicial, esse foi o que mais apresentou modificações. Pessoas de descendência alemã têm hábito de consumir muito leite, principalmente o leite cru, coletado direto da vaca, sem passar por processos de pasteurizaçáo e filtragem. Destaca-se que muitos moradores locais criam esses bovinos dentro do próprio terreno, facilitando o acesso e, além de tudo, o custo-benefício do consumo.

Além do leite de colono, incluído no QFA, foi referida a ingestão frequente de laticínios, como queijos de colono de produção própria e kochkäse, ambos inseridos no QFA. A kochkäse é um tipo de queijo típico da cultura alemá, "velho" (amanhecido) cozido, feito a partir do leite cru desnatado, que fica por um tempo em repouso à temperatura ambiente e, quando "dematurado", é cozido, formando a kochkäse ${ }^{20}$.

(GF1): "Leite todos os dias".

(GF2): "Leite é o de vaca".

(GF1 e GF3): "Aqui eles comem muito o kochkäse".

(GF2): "Kochkäse... aaaah, esse é bom".

O consumo de margarina, manteiga, maionese e, principalmente, de nata e banha de porco também é evidente no hábito alimentar pomerano. Geralmente, a nata ingerida pelos alemães é a extraída do leite da vaca cru e a banha de porco náo somente é utilizada como chimia de pão, mas também para o preparo de diversos pratos - aspectos que corroboram com os alimentos frequentemente consumidos pelos alemães, tais como produtos suínos, tanto assados quanto fritos na gordura, e defumados ${ }^{17,21}$. Além disso, o consumo de torresmo e banha de porco apresenta um propósito de proporcionar energia concentrada na alimentação de colonos que realizam trabalho "pesado" na roça ${ }^{14}$. No entanto, os alimentos e preparações ricas em gordura, quando consumidos de maneira elevada são prejudiciais à saúde, logo, devem ser evitados.

(GF1): "Requeijão, margarina, manteiga, banha de porco e nata é bastante. Faço a comida só com banha".

(GF2): "Lá em casa é só a maionese e a nata".

Os hábitos alimentares dos alemães foram adquiridos por muitos brasileiros. Todos os defumados de porco, como joelho, bisteca, costela, bacon, toucinho e torresmo, além de linguiça e salsichão, estão presentes na alimentação brasileira há muito tempo ${ }^{17}$. Os alemães têm o hábito de consumir o alimento na forma integral, aproveitando todas as suas partes, como em carnes, frutas e legumes. Esse reaproveitamento ajuda a diminuir os gastos com alimentação e a reduzir o desperdício, além de possibilitar a criação de novas receitas, como sucos, doces, geleias e farinhas ${ }^{22}$, algo muito comum na populaçáo estudada.

Em relação às carnes, percebeu-se que essa população consome desde os miúdos até as partes principais do animal. Os miúdos são utilizados na preparação de pratos típicos, como recheio do pato ou marreco, morcilha clara (leberwurst) e escura (blutwurst) e geleia de cabeça de porco (sülse 
- confeccionada com partes do cérebro do porco). Houve referência também à ingestão habitual de linguiça e língua (citadas várias vezes ao longo das entrevistas). $\mathrm{O}$ torresmo foi outro alimento bastante mencionado nos depoimentos, consumido com frequência, inclusive como aperitivo em ocasiôes festivas.

(GF3): "O cérebro do porco, a gente faz geleia".

(GF4 e GF1): "Linguiça bastante. Todos os tipos. Morcilha bastante".

(GF3): "A lingua é bastante".

(GF1): "Aqui sempre tem, vai em qualquer lugar de comer, tem molho de lingua".

(GF1): "Torresmo é bastante, às vezes no mercado tem que até reservar se quiser".

(GF2): "Lá em casa eles temperam com limão".

(GF4): "Torresmo é assim, você vai num churrasco, chega lá e o torresmo é o petisco".

Além de apresentar valores biológicos, a alimentação está envolvida também com aspectos econômicos, psicológicos, culturais e, principalmente, interligada com o convívio social da população, pois no momento da refeição com outros indivíduos são expressos sentimentos, lembranças e opinióes que a tornam um momento de confraternizaçáo. Inclusive no Brasil, as pessoas se preocupam muito mais com o prazer durante a refeiçáo do que com seu valor nutricional ${ }^{16,23,24}$. Esse convívio social ocorre em datas especiais, momentos de encontro e, principalmente, em festas comunitárias. Nessas ocasióes, as principais atraçôes são as comidas típicas ${ }^{25}$.

Nesse contexto, o alimento referido como típico e muito consumido pela população de Pomerode foi a sopa de sangue de pato, conhecida por schwarzsauer. Trata-se de uma preparação presente na maioria das festas, bem como na rotina das refeiçôes diárias.

(GF1 e GF4): "Ah, aqui eles fazem bastante em festa o sangue de pato, o schwarzsauer. Tem na despedida de solteiro e nos casamentos".

\section{GRUPOS DE BEBIDAS}

Nota-se consumo frequente de todas as bebidas presentes no QFA de partida, justificando sua permanência no QFA adaptado para a população pomerana. Entretanto, foi introduzido no novo QFA o chopp, habitualmente ingerido pela população descendente de alemães. Na maioria das festas típicas de Pomerode, o chopp é a maior atração.

\section{Grupo de doces}

Quanto à ingestão de alimentos do grupo dos doces, foi possível verificar que os pomeranos referem consumo habitual tanto dos industrializados como dos caseiros, sem exclusão de qualquer alimento do grupo que fazia parte do QFA inicial.

(GF1): "Todo restaurante quase tem sagu e o pudim".

(GF2): "Lá em casa eu faço um pudim de banho-maria".

(GF2): "A bala de banana. Essa não pode faltar em casa. Tem sempre um quilo lá".

Destaca-se a ingestão do melado que não pode faltar na casa dos pomeranos.

(GF1): "Bastante melado aqui! O conservante é o limão, eles não colocam nada. Inclusive nos doces que eles fazem, o doce de frutas é com o limão. Daqui o melado, o pessoal que tem a cultura alemã faz o melado".

Atualmente, ainda permanece o hábito da cultura alemã de misturar o doce com o salgado. Conforme Reinhardt ${ }^{15}$, o sabor agridoce agrada a muitos paladares alemães: no café da manhã, usar manteiga com a geleia para passar no pão, ou manteiga com o melado, ou, indo ao extremo e misturar requeijão com melado ou geleia com salame são hábitos frequentes.

\section{Grupo de massas e outras preparações}

Por meio das falas dos participantes nos grupos focais, notou-se que a população em questão consome frequentemente alimentos do grupo das massas, ganhando destaque a pizza e o macarrão instantâneo, que as crianças normalmente consomem puro.

Em decorrência do novo estilo de vida urbano agitado, a populaçáo teve necessidade de readaptar sua vida em função da disponibilidade de tempo, recursos financeiros, locais para realizar as refeiçóes, entre outros. Por esse motivo, fez-se necessário a utilização de produtos alimentícios industrializados ${ }^{23}$.

(GF4): "Pizza bastante. Até porque nós temos a melhor pizza da regiāo! É mais a pizza, o macarrão e o miojo!".

Além disso, uma das preparações citadas como habitual na mesa dos pomeranos é o nhoque feito com batata doce. Outros pratos frequentemente presentes são o pastelão, o chucrute no cachorro quente e o bolinho de carne no pão, inserido no novo QFA.

(GF1 e GF3): "Toda festa tem nhoque de batata, nos outros lugares é de batata inglesa, aqui é de batata doce".

(GF3): "Pastelão tem que ter, de preferência com palmito". 
(GF2): "Quando alguém vai ali no boteco tem que ter bolinho de carne. Um pão e coloca dois bolinhos de carne".

Diante dos relatos e a partir da exploraçáo do material coletado nos grupos focais, após codificação e análise dos dados, foram realizadas 21 inclusões de alimentos, representando $18,4 \%$, e 17 de exclusóes, ou $14,91 \%$ do total de questóes do QFA de partida, num total de 33,33\% de alteração do instrumento. Os alimentos incluídos foram: pão frito na banha, pão com sardinha e ovo, apfelstrudel, orelha de gato, biscoito amanteigado, cuca, maionese caseira, nêspera (ameixa do pé), leite de colono, queijo de colono, kochkäse, nata, gordura de porco, recheio de pato ou marreco, língua, schwarzsauer, geleia de cabeça de porco (sülse), nhoque de batata doce, morcilha clara (leberwurst) e escura (blutwurst), bolinho de carne e chopp.

Os alimentos excluídos foram: pão sírio, angu, cará, inhame, banana da terra cozida, caju, cajá, almeirão, quiabo, pistache, cottage, muçarela de búfala, queijo polenghi, caranguejo, siri, acarajé e outras comidas baianas, como vatapá, caruru e moqueca de peixe. Assim, dos 114 alimentos presentes no QFA de partida, o QFA adaptado passou a ter 118 alimentos, distribuídos nos mesmos grupos alimentares e com as mesmas categorias de frequência alimentar que o QFA ELSA.

É importante destacar que a adaptação realizada representou uma modificação considerável do instrumento de partida, sendo uma etapa prévia ao processo de validação do instrumento do novo QFA para o estudo em questão, que confere maior efetividade e segurança ao processo, ao adequar o instrumento à realidade da população da pesquisa.

\section{Considerações finais}

A utilização dos grupos focais demonstrou ser uma técnica apropriada para a adaptação do questionário alimentar, resultando em uma considerável alteração do QFA de partida, com inclusóes e exclusões de alimentos identificados pelos próprios participantes, a partir do seu contexto sociocultural e de seus costumes, com grande adesão a alimentos de plantio e animais de criação próprios. Ressalta-se que com a adaptação, o inquérito alimentar poderá ser utilizado no Estudo das Condiçóes de Vida e Saúde da População de Pomerode/SC com maior efetividade para o conhecimento dos hábitos alimentares daquela população. No entanto, como continuidade desta pesquisa, recomenda-se que sejam realizadas validaçáo e reprodutibilidade do novo QFA, para que, a partir de seus resultados, sejam obtidas informaçóes dietéticas corretas e úteis para posteriores inferências.

\section{Referências}

1. Alexandre LBSP. Epidemiologia aplicada nos serviços de saúde. São Paulo: Martinari; 2012.

2. John U, Hensel E, Lüdemann J, Piek M, Sauer S, Adam C, et al. Study of Health In Pomerania (SHIP): a health examination survey in an east German region: objectives and design. Soz Praventivmed. 2001;46(3):186-94.

3. Slater B, Philippi ST, Marchioni DML, Fisberg RM. Validação de questionários de frequência alimentar - QFA: consideraçôes metodológicas. Rev Bras Epidemiol. 2003;6(3):200-8.

4. Assis MAA, Benedet J, Kerpel R, Vasconcelos FAG, Pietro PF, Kupek E. Validação da terceira versão do Questionário Alimentar do Dia Anterior (QUADA-3) para escolares de 6 a 11 anos. Cad Saúde Pública. 2009;25(8):1816-26.

5. Willett WC. Nutritional Epidemiology. 2nd ed. New York: Oxford University Press; 1998.

6. Fisberg RM, Slater B, Marchioni DML, Martini LA. Inquéritos alimentares: métodos e bases científicas. Barueri: Manole; 2005.

7. Ochsenhofer K. Validação de um questionário semi-quantitativo de frequência alimentar online para ferro [dissertação]. São Paulo: Universidade de São Paulo; 2007.

8. Margetts BM, Nelson M. Design concepts in nutritional epidemiology. 2nd ed. New York: Oxford University Press; 1997.

9. López JV. Validez de la evaluación de la ingesta dietética. In: Majem LS, Bartrina JA, Verdú JM. Nutrición y salud pública: métodos, bases científicas y aplicaciones. Madrid: Masson; 1995. p. 132-6.

10. Molina MCB, Benseñor IM, Cardoso LO, VelasquezMelendez G, Drehmer M, Pereira TSS, et al. Reprodutibilidade e validade relativa do questionário de frequência alimentar do ELSA-Brasil. Cad Saúde Pública. 2013;29(2):379-89.

11. Zimmer R. Pomerode: espaços e história. Pomerode: Opet; 2011.

12. Iervolino SA, Pelicioni MCF. A utilização do grupo focal como metodologia qualitativa na promoção da saúde. Rev Esc Enferm. 2001;35(2):115-121.

13. Ressel LB, Beck CLC, Gualda DMR, Hoffmann IC, Silva RM, Sehnem GD. O uso do grupo focal em pesquisa qualitativa. Texto \& Contexto Enferm. 2008;17(4):779-86.

14. Sonati JG, Vilarta R, Silva CC. Influências culinárias e diversidade cultural da identidade brasileira: imigraçáo, regionalização e suas comidas. In: Mendes RT, Vilarta R, Gutierrez GL, organizadores. Qualidade de vida e cultura alimentar. Campinas: IPES; 2009. p. 137-147. 
15. Reinhardt JC. Dize-me o que comes e te direi quem és: alemães, comida e identidade. Curitiba: Máquina de Escrever; 2012.

16. Leonardo M. Antropologia da alimentação. ANTROPOS. 2009;3(2):1-6.

17. Braun LB. Algumas consideraçôes sobre a inserção de alemães e seus descendentes na sociedade brasileira - Colônia rio-grandense - Maracaí/SP (1950-1990). Patrimônio e Memória. 2012;8(1):207-28.

18. Nascimento APB, Alves MC, Molina SMG. Quintais domésticos e sua relação com estado nutricional de crianças rurais, migrantes e urbanas. Multiciência [Internet]. 2005 Out [citado em 2016 Out 31];(5):[15 p.]. Disponível em: http:// www.multiciencia.unicamp.br/artigos_05/rede_03_05.pdf

19. Djau MA, Barros FLA, Bento JAN, Araújo DF, Reis JNP. Estudo sobre preços de frutas de lavouras temporárias no estado do Ceará. In: Araújo JÁ, Reis JNP, Paulo EM, Mancal A, organizadores. Desafios da sustentabilidade no semiárido nordestino. Fortaleza: RDS Editora; 2014. p. 214-29.
20. Silva MCG. O kochkäse como produto tradicional feminino e seu inventário como patrimônio cultural imaterial do Vale do Itajaí/SC. Anais da 29. Reunião Brasileira de Antropologia; 2014 ago. 3-6; Natal, Rio Grande do Norte, Brasil.

21. Carneiro HS. Comida e sociedade: significados sociais na história da alimentação. História: Questóes \& Debates. 2005;(42):71-80.

22. Gondim JAM, Moura MFV, Dantas AS, Medeiros RLS, Santos KM. Composição centesimal e de minerais em cascas de frutas. Ciênc Tecnol Aliment. 2005;25(4):825-7.

23. Garcia RWD. Reflexos da globalização na cultura alimentar: consideraçôes sobre as mudanças na alimentação urbana. Rev Nutr. 2003;16(4):483-92.

24. Assunção VK. Comida de mãe: notas sobre alimentação, família e gênero. Cad Espaço Feminino. 2008;19(1):233-53.

25. Rekowsky CJ, Dofrman A. Lugares, mesas e falas: comida alemã e italiana em restaurantes de Porto Alegre/RS. Ateliê Geográfico. 2013;7(1):122-42.

\section{Como citar este artigo:}

Rosa AC, Schmitz B, Chiarelli G, Silveira JLGC, Alves MU, Campanella CA. Adaptação de um inquérito alimentar a ser utilizado em um estudo longitudinal a partir do contexto sociocultural de uma população de colonização alemã. Rev. Aten. Saúde. 2016;14(50):34-41. 